Original Article

\title{
IDENTIFICATION AND QUANTIFICATION OF PHOSPHODIESTERASE-5 INHIBITORS AS ADULTERANTS IN DIETARY SUPPLEMENTS MARKED FOR SEXUAL ENHANCEMENT IN THE LEBANESE MARKET
}

\author{
RAZAN SOUBRA4 , AZZA A. GAZY1* ${ }^{*}$, MAY SAAB ${ }^{2}$, MARWA K. AL JAMAL ${ }^{3}$ \\ Department of Pharmaceutical Technology, Faculty of Pharmacy, Beirut Arab University, Beirut, Lebanon \\ Email: a.ghazi@bau.edu.lb
}

Received: 02 Dec 2019, Revised and Accepted: 29 Jan 2020

\section{ABSTRACT}

Objective: Ultraviolet Visible spectrophotometric was adopted to identify and quantify any adulteration with PDE-5 inhibitors (Sildenafil and Tadalafil) in selected dietary supplements used for sexual enhancement in the Lebanese market

Methods: Nine dietary supplements, randomly collected from Lebanese pharmacies, were screened for Sildenafil and Tadalafil using UVspectrophotometry for both qualitative and quantitative detection.

Results: Tadalafil was detected in one sample at a dose of $59 \mathrm{mg} /$ dosage unit, with the maximal recommended dose being 20 mg. Sildenafil was detected in five samples at doses ranging from 11.7 to $188.2 \mathrm{mg} /$ dosage unit, with the maximal recommended dose being $100 \mathrm{mg}$

Conclusion: This study demonstrates that regular analysis of supposed dietary supplements is needed for more effective quality control and health promotion. The method described for the extraction, identification and quantification of Tadalafil and Sildenafil would be useful for regulatory detection of adulterations.

Keywords: Adulteration, PDE-5 inhibitors, Sildenafil, Tadalafil, Herbal supplements, Spectrophotometry

(C) 2020 The Authors. Published by Innovare Academic Sciences Pvt Ltd. This is an open access article under the CC BY license (http://creativecommons.org/licenses/by/4.0/) DOI: http://dx.doi.org/10.22159/ijpps.2020v12i3.36527. Journal homepage: https://innovareacademics.in/journals/index.php/ijpps

\section{INTRODUCTION}

The popularity of herbal supplements as effective substitutes for synthetic drugs has increased worldwide in the recent years [1]. The reason for this high popularity is the common belief that herbal drugs are safe and can be used without medical supervision [2]. Moreover, the majority of patients trust herbal supplements manufacturers and believe their claims [3]. Most of these herbal preparations are available in the market as over-the-counter (OTC) dietary supplements and thus, are subject to food legislation policies which does not obligate efficacy studies, safety assessment, or quality control [4]

Unfortunately, many studies have reported the adulteration of herbal products with undeclared pharmaceutical ingredients, even at higher levels than the maximum recommended dose, and consumers are unaware of these counterfeit products [5].

The Food and Drug Administration (FDA) reported 572 adulterated dietary supplements between 2007 and 2014 in the United States, of which the most common were sexual enhancers (41.6\%) [1]. Most of these adulterants were phosphodiesterase type five (PDE-5) inhibitors (Sildenafil, Tadalafil, Vardenafil and their analogues). The majority of reports were from Asian countries (67\%), followed by Europe (22\%) and North America (11\%), and the most frequently reported adulterants were sildenafil analogues (62\%), followed by tadalafil (26\%) and vardenafil (9\%) [6].

Phosphodiesterase type 5 inhibitors are the leading oral drug for pharmacological treatment of erectile dysfunction (ED) [3]. They are recommended as the first line of treatment by both the European and American urological guidelines [7]. However, they must be used under medical supervision as they may predispose the consumer to potentially severe drug-drug interactions such as the development of lifethreatening hypotension when used in combination with nitrates [4].

It is obvious that the unaware usage of such preparations is dangerous as the risk of adulterated drugs use overweighs their benefits, especially in patients with co-morbid conditions such as cardiovascular complications and diabetes and even polypharmacy in older adults pursuing effective and safe alternatives to PDE-5 inhibitors [2]

Up to now, 80 illicit analogues of PDE-5 inhibitors have been discovered, and unfortunately, the number is rising [4]. Campbell et al. tested 91 herbal products that were mostly in the United States and Asia. None of the samples claimed to include synthetic drugs, however, PDE-5 inhibitors were detected in 74 of them (81\%), most of which were Tadalafil and/or Sildenafil, often at amounts higher than the maximum approved dose [8]

In France, 61\% of 150 herbal sexual enhancers marked as 100\% natural preparations were found to contain PDE-5 inhibitors [9].

A study conducted in Malaysia has reported that $82 \%$ of 62 products that claimed to enhance man's sexual health, were adulterated with one or more PDE-5 inhibitors and analogues, and one of the samples was found to contain even 5 different PDE-5 inhibitors [10].

In Iran, an analysis of 80 herbal products sold as sexual enhancers showed that 22 samples (27.5\%) contained at least one undeclared pharmaceutical ingredient. Sildenafil was found in 19 samples, and 3 samples were adulterated with a mixture of tramadol, diazepam, and sildenafil [5].

In a study conducted in Egypt, five of the most popular food supplements used for the treatment of erectile dysfunction were selected for analysis from over 50 products available in the Egyptian market (OTC and teleadvertised). Undeclared sildenafil was detected in all analyzed products in amounts reaching to $180 \mathrm{mg}$ per single dose [11].

The success of PDE- 5 inhibitors for the treatment of ED, the risks they propose, and the widespread adulteration, raises the question of whether dietary supplements used as sexual enhancers in Lebanon are adulterated by synthetic drugs. However, to our knowledge, there aren't any reported analysis of dietary supplements marked for sexual enhancement in the Lebanese market.

Upon screening the literature of the PDE-5 inhibitors (Tadalafil and Sildenafil), several analytical methods have been used for their 
quantitative and qualitative detection. These include; nuclear magnetic resonance (NMR) spectroscopy [9], liquid chromatography (LC), high performance liquid chromatography (HPLC), ultra-high performance liquid chromatography (UHPLC) coupled to ultraviolet/diode array detector (UV/DAD) [6], mass spectrometry (MS), ultraviolet (UV) spectroscopy, and Fourier transform infrared spectroscopy associated with attenuated total reflection (FTIR-ATR) [12-14].

Spectroscopic methods have been suggested as an on-field screening tool to be used by customs that are frequently confronted with large numbers of products suspected to be adulterated and require analytical inspection. That is because these methods are known to be rapid, simple to use, have high throughput, and require little sample preparation [12]. For this reason, in our work, the analytical method used is UV spectrophotometry $[15,16]$.

The aim of the present study is to identify and quantify any adulteration with PDE-5 inhibitors (sildenafil and tadalafil) in selected dietary supplements used for sexual enhancement in the Lebanese market using UV spectrophotometric method.

\section{MATERIALS AND METHODS}

\section{Standards and reagents}

Reference standards of Sildenafil citrate and Tadalafil were certified to contain 99.7\% (PHARMADEX S. A. L, BEIRUT, LEBANON). Methanol of analytical grade (SIGMA-ALDRICH, CHROMASOLV ${ }^{\circledR}$ ). Nine products randomly purchased from different local pharmacies in Beirut were selected for testing. Their dosage from, ingredients and manufacturing details are tabulated in table 1.

\section{Instrumentation}

Jasco V-730 double beam UV-Vis Spectrophotometer interfaced to a computer programmed with Jasco Spectra Manager software was used for spectrophotometric measurements, spectral acquisition and elaboration. A pair of $1 \mathrm{~cm}$ quartz cells were used to measure the absorption spectra.

Table 1: Specifications of the tested products

\begin{tabular}{|c|c|c|c|c|c|}
\hline $\begin{array}{l}\text { Sample } \\
\text { code }\end{array}$ & Batch number & Expiry date & Ingredients & $\begin{array}{l}\text { Country } \\
\text { origin }\end{array}$ & Dosage form \\
\hline S01 & 01180121 & $01 / 2021$ & Epimedium, Ginkgo Biloba, Panax Ginseng, Royal Jelly & China & $\begin{array}{l}\text { Hard gelatin } \\
\text { capsule }\end{array}$ \\
\hline S02 & (none) & $14 / 06 / 2020$ & Ginseng Alijao, root of membranous milk vetch & China & $\begin{array}{l}\text { Hard gelatin } \\
\text { capsule }\end{array}$ \\
\hline S03 & 120617110622 & $11 / 06 / 2022$ & $\begin{array}{l}\text { Raspberry, Solomonscal Rhizome, Chinese Yam Rhizome, } \\
\text { Barbary Wolfberry Fruit, Cassia Bark }\end{array}$ & China & $\begin{array}{l}\text { Hard gelatin } \\
\text { capsule }\end{array}$ \\
\hline S04 & 20085 & $11 / 2020$ & $\begin{array}{l}\text { Epimedium, Tribulus Terrestris, Ginkgo biloba, Hypericum } \\
\text { perforatum, Cistanche, Crataegus Oxycantha }\end{array}$ & Lebanon & $\begin{array}{l}\text { Hard gelatin } \\
\text { capsule }\end{array}$ \\
\hline S05 & 18022 & $02 / 2021$ & $\begin{array}{l}\text { Pomegranate Extract, Broccoli Extract, Curcumin, Bromelain, } \\
\text { Quercetin, Lycopene, Resveratrol, BioPerine®, Zinc, Copper, } \\
\text { Selenium }\end{array}$ & Lebanon & $\begin{array}{l}\text { Hard gelatin } \\
\text { capsule }\end{array}$ \\
\hline S06 & 0203R & $03 / 2021$ & $\begin{array}{l}\text { Korean Ginseng Extract, Ginkgo Biloba Extract, Vitamin C, } \\
\text { Vitamin E, Zinc, Selenium, L-Arginine, L-Carnitine, L-Methionine, } \\
\text { L-Phenylalanine }\end{array}$ & England & Tablet \\
\hline S07 & (none) & $30 / 12 / 2020$ & Ginkgo Biloba, Epimedium Sagitatum, Tongkat Ali, Panax Ginseng & Spain & Tablet \\
\hline S08 & (none) & $30 / 12 / 2020$ & Angelica, Clove Dong Quai & Spain & $\begin{array}{l}\text { Soft Gelatin } \\
\text { capsule }\end{array}$ \\
\hline S09 & 140111 & $04 / 2021$ & $\begin{array}{l}\text { Pure honey 97\%, Eurycoma Longifolia, Panax Ginseng, Bee Larva } \\
\text { Powder }\end{array}$ & Malaysia & Syrup \\
\hline
\end{tabular}

\section{Standards and samples preparation}

\section{Preparation of standard stock solution}

Standard stock solutions $(1 \mathrm{mg} / \mathrm{ml}$ ) were prepared by accurately weighing and transferring $50 \mathrm{mg}$ Sildenafil citrate or Tadalafil into two separate $50 \mathrm{ml}$ volumetric flasks. To each flask, $20 \mathrm{ml}$ methanol were added, sonicated for $5 \mathrm{~min}$, and diluted to the mark with the same solvent.

\section{Preparation of standard working solutions}

Accurate volumes from Sildenafil and Tadalafil standard stock solutions were transferred into $50 \mathrm{ml}$ volumetric flasks and diluted to the mark with methanol, to obtain two different standard working solutions of $100 \mu \mathrm{g} / \mathrm{ml}$ each.

\section{Calibration curve}

Aliquots of the standard working solutions were transferred into series of $10 \mathrm{ml}$ volumetric flasks, to obtain a calibration set in the range of $10-40 \mu \mathrm{g} / \mathrm{ml}$, using methanol as a solvent.

\section{Pharmaceutical application}

Four dosage units (powdered tablets, capsule content, or syrup) of each product were weighed and mixed. Average weight equivalent to one dosage unit was transferred into a $50 \mathrm{ml}$ volumetric flask,
$30 \mathrm{ml}$ methanol were added and the mixture was sonicated for 20 min. Another $10 \mathrm{ml}$ methanol was then added and sonicated for an additional $10 \mathrm{~min}$. The prepared mixture was then filtered and made up to $50 \mathrm{ml}$ with methanol. From the prepared solution, a volume of $0.1 \mathrm{ml}$ was transferred into $10 \mathrm{ml}$ volumetric flask and made up the mark with methanol. The absorbance value of this solution was then measured in the range of 200-400 $\mathrm{nm}$ at $0.5 \mathrm{~nm}$ interval, using methanol as blank.

\section{RESULTS AND DISCUSSION}

The UV absorption spectra of Tadalafil (fig. 1) and Sildenafil (fig. 2) showed maximum absorption at $284 \mathrm{~nm}$ and $291 \mathrm{~nm}$, respectively. The UV absorption spectra obtained from the tested products showed spectrum corresponding to Tadalafil in sample S01 (fig. 3) and spectra corresponding to Sildenafil in samples S02, S03, S04, S07, and S09 (fig. 4, 5, 6, 9, and 11, respectively). Whereas samples S05, S06, and S08 spectra were not in correspondence to tadalafil or sildenafil (fig. 7, 8, and 10, respectively).

Calibration curves were constructed at a maximum wavelength of $284 \mathrm{~nm}$ and $291 \mathrm{~nm}$ for Tadalafil and Sildenafil, respectively (fig. 12 and 13). Calculations were carried out using absorbance of each sample at 284 or $291 \mathrm{~nm}$ (Tadalafil or Sildenafil, respectively) in correspondence with the calibration curve. The results obtained are presented in table 2 . 


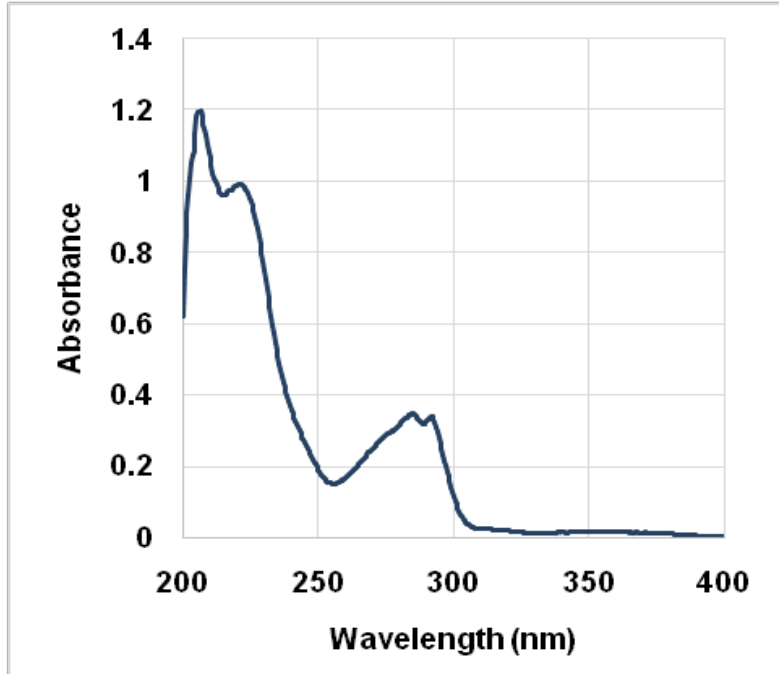

Fig. 1: Absorption spectrum of $10 \mu \mathrm{g} / \mathrm{ml}$ standard tadalafil in methanol

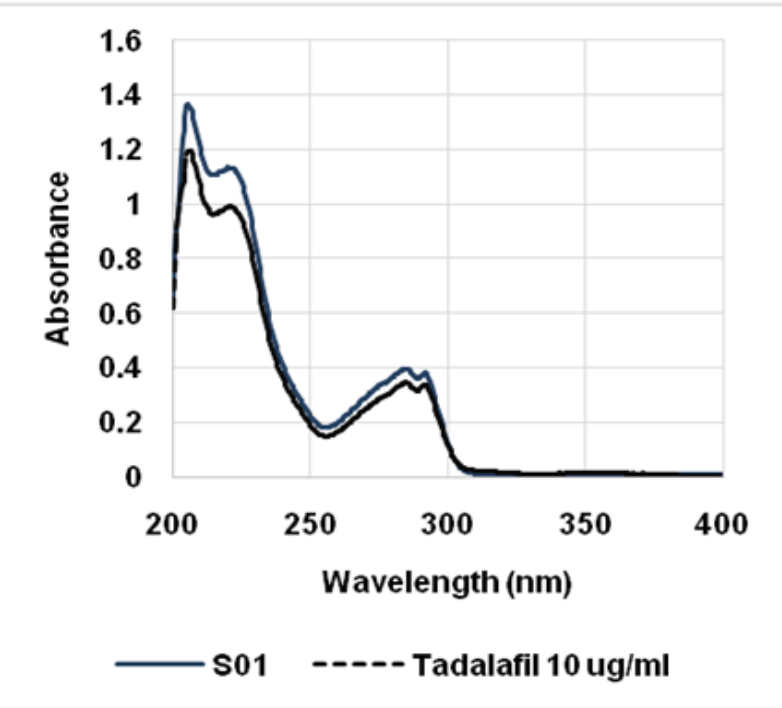

Fig. 3: Absorption spectrum of sample S01

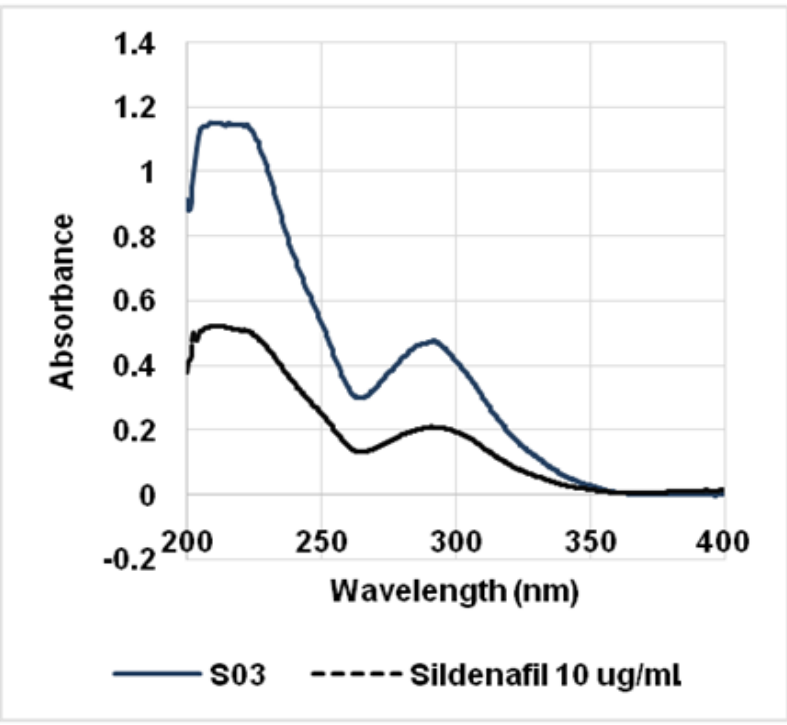

Fig. 5: UV Absorption spectrum of sample S03

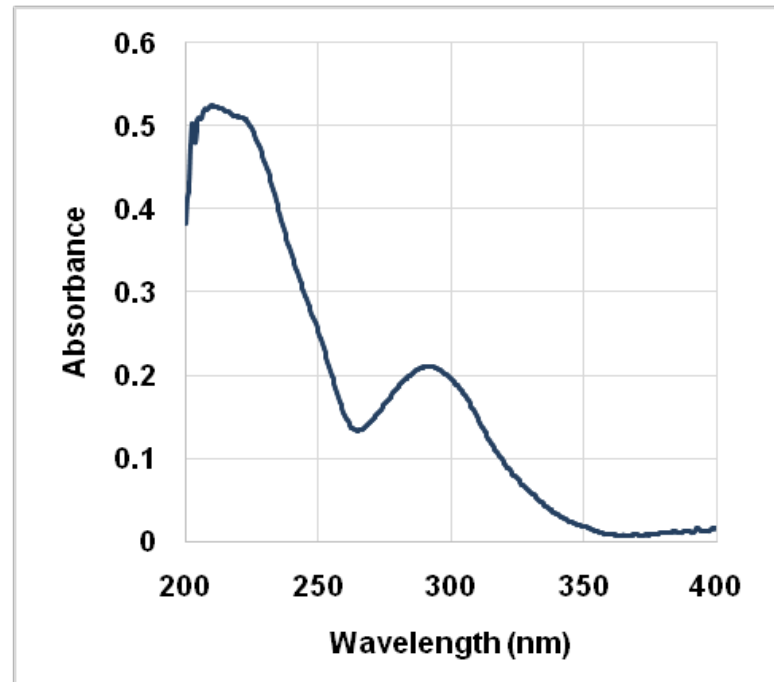

Fig. 2: Absorption spectrum of $10 \mu \mathrm{g} / \mathrm{ml}$ standard sildenafil in methanol

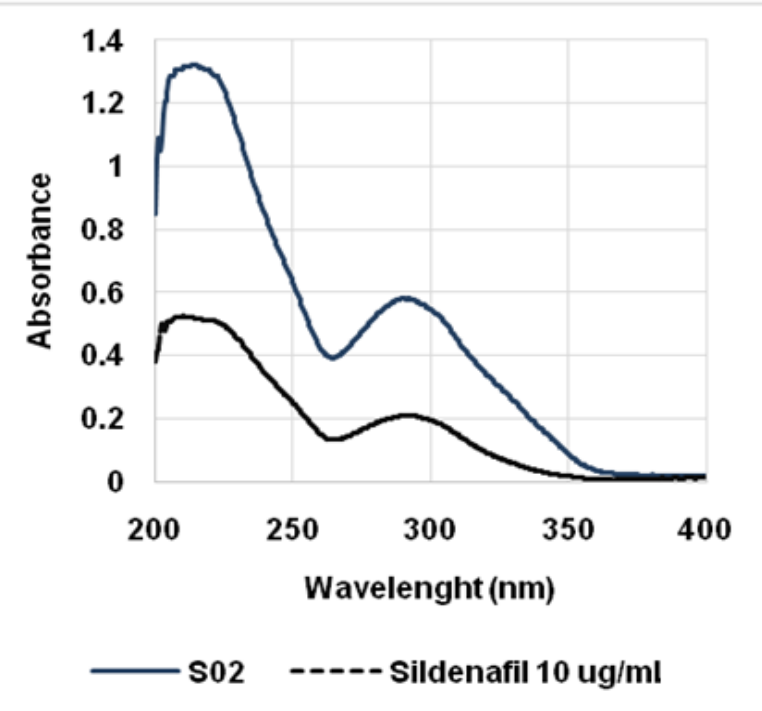

Fig. 4: Absorption spectrum of sample S02

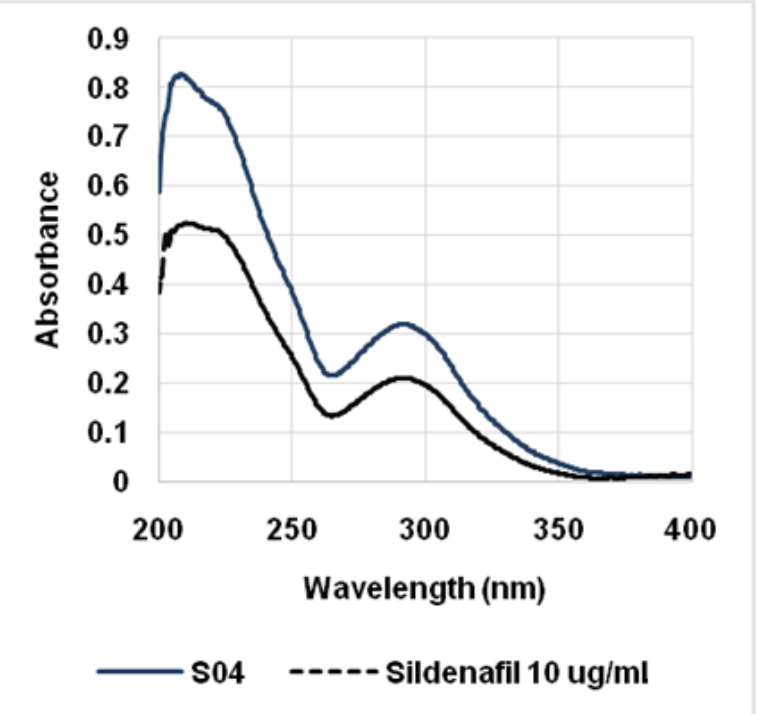

Fig. 6: Absorption spectrum of sample S04 


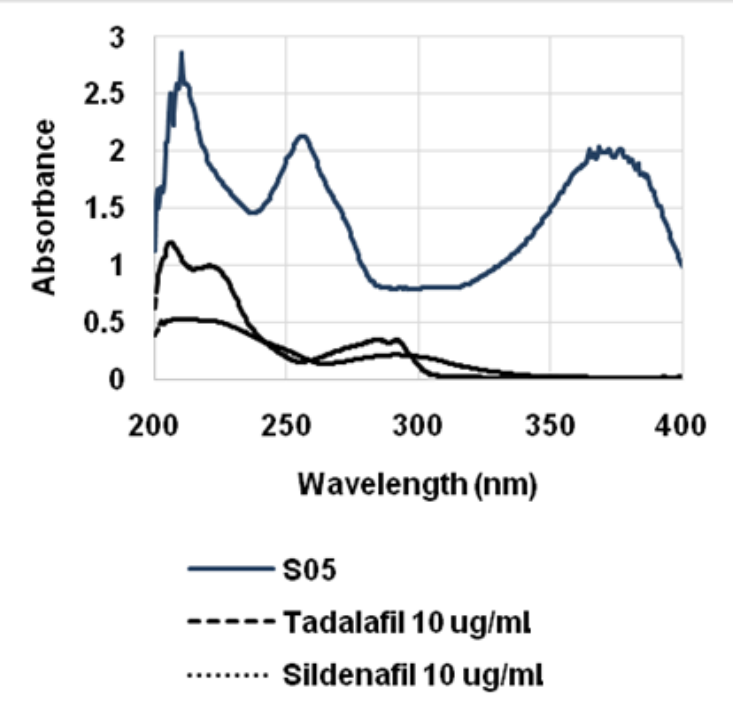

Fig. 7: Absorption spectrum of sample S05

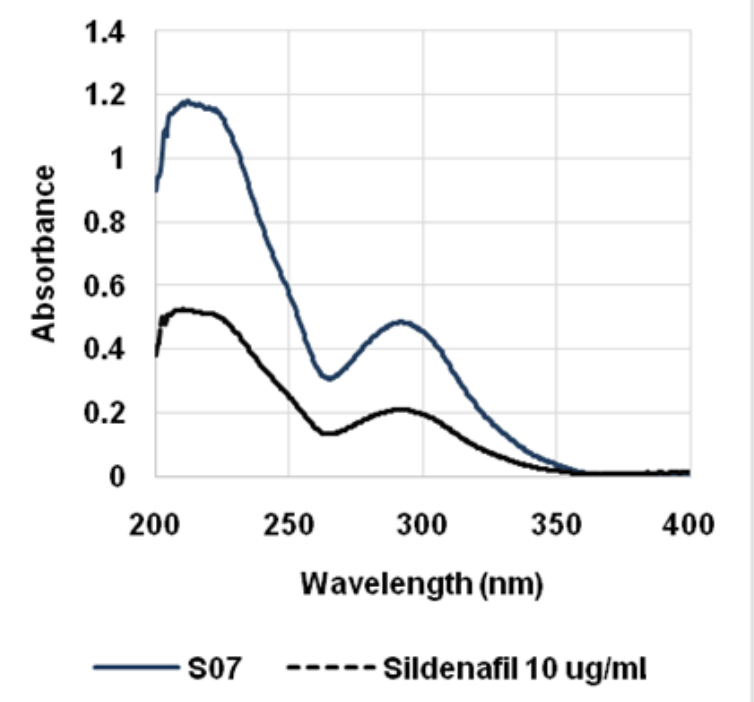

Fig. 9: Absorption spectrum of sample S07

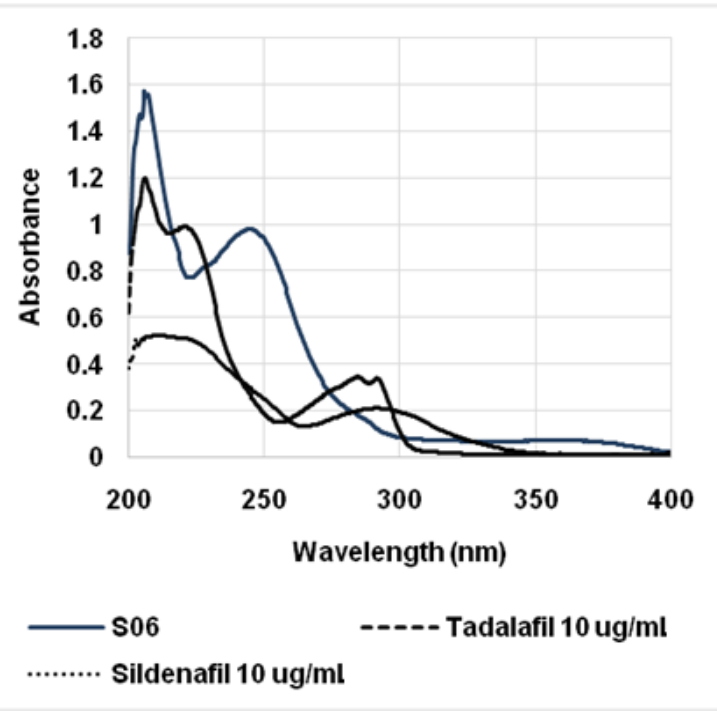

Fig. 8: Absorption spectrum of sample S06

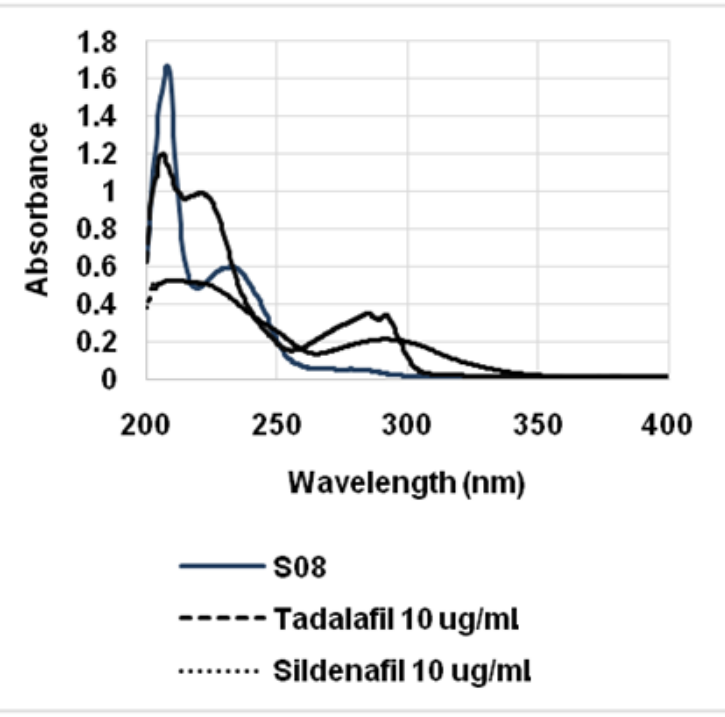

Fig. 10: Absorption spectrum of sample S08

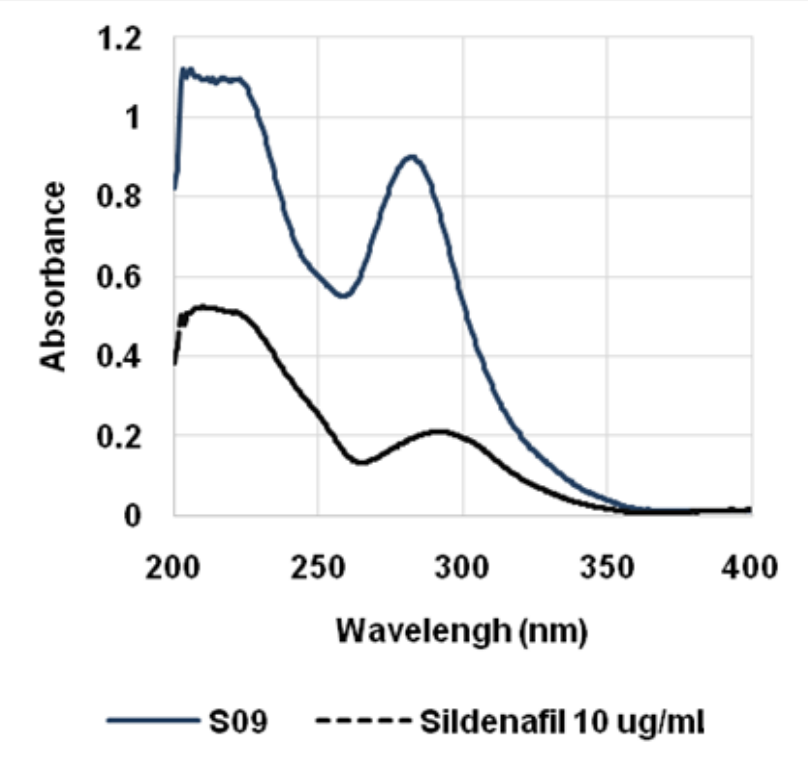

Fig. 11: Absorption spectrum of sample S09 


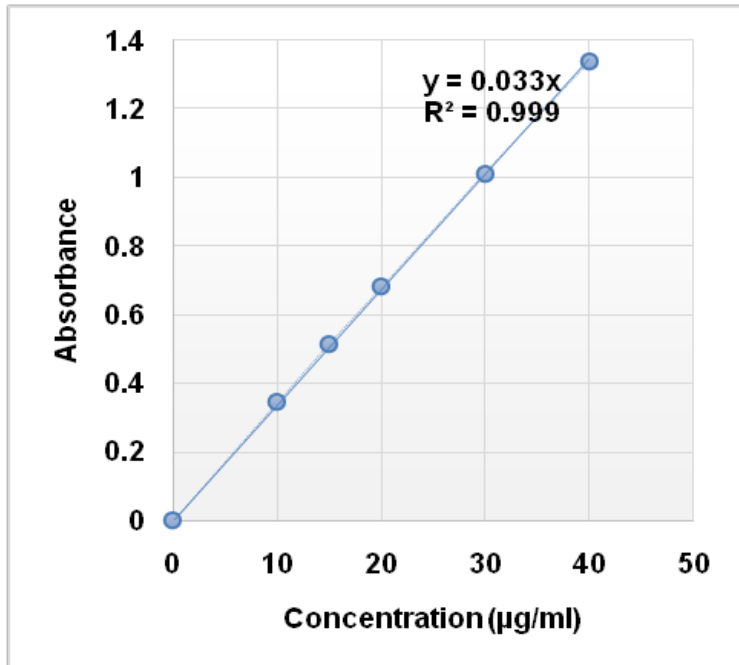

Fig. 12: Calibration curve of tadalafil at $\lambda_{\max }=284 \mathrm{~nm}$

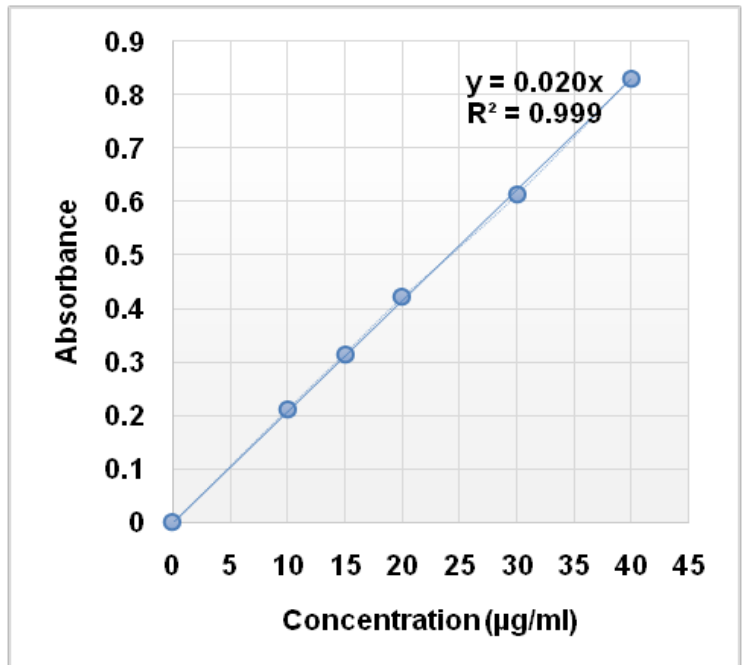

Fig. 13: Calibration curve of sildenafil at $\lambda_{\max }=291 \mathrm{~nm}$

Table 2: Qualitative and quantitative results of the tested products

\begin{tabular}{lll}
\hline Sample code & Adulterant detected & Mean Amount per dosage unit (mg)* $\mathbf{S D}$ \\
\hline S01 & Tadalafil & $59.0 \pm 0.65$ \\
S02 & Sildenafil & $140.0 \pm 0.33$ \\
S03 & Sildenafil & $115.0 \pm 0.73$ \\
S04 & Sildenafil & $77.0 \pm 0.44$ \\
S05 & Negative & - \\
S06 & Negative & - \\
S07 & Sildenafil & $11.70 \pm 0.32$ \\
S08 & Negative & - \\
S09 & Sildenafil & $188.20 \pm 0.54$ \\
$*$ Mean of samples 5 & & \\
\hline
\end{tabular}

Tadalafil was detected in one formulation at a dose higher than 20 $\mathrm{mg} /$ dosage unit, the maximal recommended dose. Sildenafil was detected in five formulations at doses ranging from 11.7 to 188.2 $\mathrm{mg} /$ dosage unit, with three containing more than $100 \mathrm{mg} /$ dosage unit, the maximal recommended dose. These results are in accordance with other studies that reported adulteration with PDE-5 inhibitors at doses higher than the maximal recommended dose $[9,17,18]$.

It is worthy to note that the labeled method of administration of most of the tested products was 1-2 tablets to be taken 2-3 h before sexual intercourse, while some were advised to be taken on daily basis. However, to our knowledge, there are no reported data about the effectiveness of herbal remedies in improving sexual performance when taken as a single dose before sexual intercourse.

One of the definitions of substandard and falsified (SF) medical products is "medical products that deliberately/fraudulently misrepresent their identity, composition or source". Therefore, adulterated herbal products are not determined as herbal medicine by the World Health Organization (WHO) [19].

Several studies showed that PDE-5 inhibitors were detected in adulterated herbal products present in the market and advertised on the internet to improve sexual performance [12]. In accordance with the results of the present study, 6 out of 9 products tested were adulterated with Tadalafil or Sildenafil, as shown in table 2.

The safety profile of such products is of dangerous health concern. Several guidelines that were set by the WHO provide practical guidance for monitoring the safety of herbal medicines, such as pharmacovigilance systems, 'Good manufacturing practice (GMP)' for dietary supplements and proper labelling of herbal products [20]

The European Union (EU) members consider dietary supplements as food, and they are subjected to the disposition of the General Food Law which set standards for maintaining food safety. Unfortunately, in many other countries, this area is not appropriately regulated [7].
In Lebanon, a committee affiliated to the Ministry of Public Health (MOPH) is responsible for the examination of all the submitted applications to permit the manufacturing or importing of herbal products and food supplements. Upon submission of applications, applicants must provide a certificate of analysis and methods of analysis issued by an officially recognized laboratory [21]. Moreover, the continuous control in dispensing adulterated herbal products inside pharmacies is subject to the inspection of the MOPH, while other points of sales remain under the control of the Consumer Protection Department of the Ministry of Economy and Trade [22].

The high prevalence of adulteration of herbal products, combined with the massive growing consumption of dietary supplements, necessitate the need to develop rapid and sensitive methods for detecting adulterants to protect the public from dangerous fraudulent practices.

\section{CONCLUSION}

Among nine dietary supplements analyzed, six were adulterated with PDE-5 inhibitor. Some even contained doses higher than the maximal recommended dose. The method described for the extraction, identification and quantification of Tadalafil and Sildenafil would be useful for regulatory detection of adulterations.

It is recommended to implement the role of Ministry of Public Health in collaboration with the Ministry of Economy and Trade in inspecting random samples of the dietary supplement from the point of arrival (port), or point of domestic manufacturing, before being distributed in the Lebanese market. In addition to routine and random inspections as long as available in the Lebanese market.

\section{ACKNOWLEGMENT}

The authors wish to thank the Faculty of Pharmacy at Beirut Arab University for necessary facility required for accomplishing this research work. 


\section{AUTHORS CONTRIBUTIONS}

Razan Soubra performed the experiments and the measurements. Azza A. Gazy was involved in planning, design and supervised the work. May Saab, Marwa k. al Jamal processed the experimental data along with the calculations, designed the fig. and interpreted the results. Azza a. Gazy, May Saab, Marwa k. al Jamal revised the results and drafted the manuscript.

\section{CONFLICTS OF INTERESTS}

The authors declare that there are no conflicts of interest

\section{REFERENCES}

1. Skalicka Wozniak K, Georgiev MI, Orhan IE. Adulteration of herbal sexual enhancers and slimmers: the wish for better sexual well-being and perfect body can be risky. Food Chem Toxicol 2017;108:355-64.

2. Bhagavathula AS, Elnour AA, Shehab A. Pharmacovigilance on sexual enhancing herbal supplements. Saudi Pharm J 2016;24:115-8.

3. Mustabasic N, Isik S. Determination of sildenafil mixed into herbal honey mixture by ultra-performance liquid chromatography-quadrupole time of flight mass spectrometry. Croat J Food Sci Technol 2017;9:168-72.

4. Ekar T, Kreft S. Common risks of adulterated and mislabeled herbal preparations. Food Chem Toxicol 2019;123:288-97.

5. Fard HH, Akhgari M. Analytical perspectives of chemical adulterants in herbal sexual enhancer drugs. J Pharm Pharmacol 2018;6:45-53.

6. Mohammad Al-Amin, Gazi N Sultana, Chowdhury F. Hossain identification of sildenafil citrate as an adulterant in herbal products using high-performance liquid chromatography with photodiode array detector. Int J Pharm Pharm Sci 2018;10:15-20.

7. Zuntar I, Krivohlavek A, Kosic Vuksic J, Granato D, Bursac Kovacevic D, Putnik P. Pharmacological and toxicological health risk of food (herbal) supplements adulterated with erectile dysfunction medications. Curr Opin Food Sci 2018;24:9-15.

8. Campbell N, Clark JP, Stecher VJ, Thomas JW, Callanan AC, Donnelly BF, et al. Adulteration of purported herbal and natural sexual performance enhancement dietary supplements with synthetic phosphodiesterase type 5 inhibitors. J Sex Med 2013;10:1842-9.

9. Gilard V, Balayssac S, Tinaugus A, Martins N, Martino R, Malet Martino M. Detection, identification and quantification by $1 \mathrm{H}$ NMR of adulterants in 150 herbal dietary supplements marketed for improving sexual performance. J Pharm Biomed Anal 2015;102:476-93.

10. Bujang NB, Chee CF, Heh CH, Rahman NA, Buckle MJC. Phosphodiesterase-5 inhibitors and their analogues as adulterants of herbal and food products: analysis of the Malaysian market, 2014-16. Food Addit Contam Part A 2017;34:1101-9.
11. ElAgouri G, ElAmrawy F, ElYazbi A, Eshra A, Nounou MI. Male enhancement nutraceuticals in the middle east market: claim, pharmaceutical quality and safety assessments. Int J Pharm 2015;492:109-19.

12. Rocha T, Amaral JS, Oliveira MBPP. Adulteration of dietary supplements by the illegal addition of synthetic drugs: a review. Compr Rev Food Sci Food Saf 2016;15:43-62.

13. Clahan J, Howard D, J Almalki A, P Gupta M, L Calderon A. Chemical adulterants in herbal medicinal products: a review. Planta Med 2016;82:505-15.

14. Amir A Sakur, Shaza A. Validated spectrophotometric method to determine vardenafil and sildenafil in pharmaceutical forms using potassium iodide and potassium iodate. Int J Pharm Pharm Sci 2017;9:65-9.

15. Baokar S, Pawar V, Patil RN, Jagatap R, Ekatpure N. Validation of simple and rapid UV-spectrophotometric method with stress degradation study for sildenafil citrate. Res J Pharm Technol 2012;5:214-8.

16. Yunoos M, Sankar DG, Kumar BP, Hameed S. UV spectrophotometric method for the estimation of tadalafil in bulk and tablet dosage form. E J Chem 2010;7:833-6.

17. Elrasheed G, Magdi Awadalla M, SM A. Adulteration of herbal preparations with sildenafil and tadalafil. The Sixth Annual Post-graduate Studies and Scientific Research Conference. Khartoum, Sudan; 2015.

18. Agrawal SS, Mishra G. Adulteration of synthetic PDE-5 inhibitors viz., sildenafil and tadalafil in marketed herbal aphrodisiacs. Curr Med Res Pract 2016;6:152-6.

19. WHO. Definitions of substandard and falsified (SF) medical products. WHO. World Health Organization; 2017. Available from: https://www.who.int/medicines/regulation/ssffc/ definitions/en/ [Last accessed on 29 Sep 2019]

20. WHO guidelines on safety monitoring of herbal medicines in pharmacovigilance systems. Available from: https://apps.who.int/medicinedocs/en/m/abstract/Js7148e/ [Last accessed on 29 Sep 2019]

21. Decree 5518 concerning the regulation of import, export, sale, manufacture, and packaging of food supplements and natural products of health benefits and the determination of the relevant committee and compensation of its sessions. Lebanese Ministry of Public Health; 2010. Available from: https://www.moph.gov.lb/userfiles/files/SanitaryEngineering /FoodSupplements/Decree 5518-10.pdf. [Last accessed on 14 Dec 2010]

22. Decision of the Minister of Health No. 841 concerning the control over the marketing of therapeutic preparations and dietary supplements. Lebanese Ministry of Public Health; 2012. Available from: https://www.moph.gov.lb/userfiles/files/SanitaryEngineering /FoodSupplements/karar841-2012.pdf [Last accessed on 22 Jul 2012]. 